\section{Why are they hard to treat? A preliminary survey to predict important factors causing persistent scabies among students of religion-affiliated boarding schools in Indonesia}

\author{
Rahadi Rihatmadja, Eliza Miranda, \\ Melani Marissa Wicaksono, \\ Sandra Widaty \\ Department of Dermatology and \\ Venereology, Faculty of Medicine \\ Universitas Indonesia - Dr. Cipto \\ Mangunkusumo National Referral \\ Hospital, Jakarta, Indonesia
}

\begin{abstract}
Scabies is difficult to treat in some settings. By observation, it is highly prevalent among students of religion-affiliated boarding schools in Indonesia. Treatment often results in temporary relief. It is known that treatment alone will fail if personal hygiene and environment problems are not addressed. The aforementioned boarding schools have certain challenging characteristics, and several studies have found they might influence those problems. Our study aimed to specify and describe the characteristics to prepare future mass treatment in tackling with the problems. The study recruited and interviewed 105 students of a boarding school located in West Java region. The problems identified were sharing clothes/prayer attire among students, infrequent washing of clothes, availability of hot water, sharing beds, lack of bed sheet, and the presence of scabies among friends and siblings at home. A successful treatment plan must provide means to improve these habits.
\end{abstract}

\section{Introduction}

Scabies, the parasitic skin infestation by Sarcoptes scabiei mite, is notoriously difficult to treat if factors related to patient's personal hygiene and environment are not addressed properly. ${ }^{1}$ Its prevalence is still high even in great cities of Indonesia, such as Jakarta. Visit to physician's office by patients from pediatric or teenage groups are usually more frequent during school holidays. Typically, they are students at boarding schools where transmission is thought to occur. Most have experienced multiple episodes that have been treated with some success but recur, forcing them to see the doctor again. Even when taking history from adult patients, it is not uncommon to find that contact with those youngsters is acknowledged, be they the (grand)children or relatives.

Treating the whole family along with the patient is assuredly burdensome as some members may not be covered by insurance. Therefore, it is important to deal with the infestation right from where it starts: the school.

Religion-affiliated boarding schools (locally known as pesantren) are quite unique to, and popular in Indonesia. Some are modern by the country's standards, but others may not be as fortunate. While clean water is mostly available, patients from the schools often cite overcrowded dormitory and skin diseases among the pupils. Problems related to itch caused by scabies are so rampant but quite accepted.

Treating only the index patient and family members will not solve the problem in this setting in the long run; it is even doubtful that mass treatment of the students will guarantee complete eradication of scabies, without at first identifying factors that favor the transmission in those schools and later contribute to the failure to keep the students disease-free, and then acting upon them.

Several studies have been carried out to identify those factors. With minor variations, almost all pointed to poor personal and/or environmental hygiene. However, in some reports, what constituted poor hygiene was not clearly documented; some studies directly measured the presence of risk factors while others only the level of knowledge among participants. ${ }^{2-5}$

We conducted a small preliminary survey to figure out factors that might hinder scabies elimination among students of a boarding school in Bogor, West Java Province, as part of study on scabies and mass treatment initiated by our institution. The study had been approved by our institution's ethical committee.

\section{Materials and methods}

Conducted in December 2017, the study randomly selected subjects from every class to be examined and interviewed by three dermatologists. The diagnosis of scabies was based on criterion used in our institution: 1) night-time itch, 2) itch among people living in the same household/group, 3) burrows (or any characteristic lesions) in
Correspondence: Rahadi Rihatmadja, Department of Dermatology and Venereology, Faculty of Medicine Universitas Indonesia Dr. Cipto Mangunkusumo National Referral Hospital, Jl. Kebon Bawang VI/31 Tanjung Priok, Jakarta 14320 , Indonesia.

Tel: +6281316960957

E-mail: rihatmadja@live.com

Key words: scabies, boarding school, clothing, bedding.

Contributions: RR, MMW, developed the questionnaire; EM, SW prepared the study flow and examination method/checklist of the students; RR, manuscript writing; EM, SW, MMW manuscript reviewing.

Conflict of interest: the authors declare no conflict of interests.

Further details: This study was part of a larger study conducted by the Department of Dermatology and Venereology, Faculty of Medicine Universitas Indonesia - Dr. Cipto Mangunkusumo National Referral Hospital, Jakarta, aimed to eradicate scabies prevalent among religious-affiliated boarding school students in Indonesia.

Acknowledgments: We thank Drs. Adhimukti T. Sampurna, Yudo Irawan, and the residents of the Department of Dermatology and Venereology at our institution. Special thanks go to Drs. R. Inge Sanityoso, Yenny Rahmawati, and Aria Kekalih who organized the event - for both the studies and treatment, and Dr. Danny Surya, who diligently collected the data.

Received for publication: 1 February 2019. Accepted for publication: 11 February 2019.

This work is licensed under a Creative Commons Attribution-NonCommercial 4.0 International License (CC BY-NC 4.0).

CCopyright R. Rihatmadja et al., 2019

Licensee PAGEPress, Italy

Dermatology Reports 2019; 11(s1):8033 doi:10.4081/dr.2019.8033

scabies's locations of predilection, and 4) findings of mite/egg under the microscope. Even though dermoscopic examination was performed, the findings were not required for making diagnosis of scabies due to low sensitivity; its use was related to other ongoing studies at that time. Subjects having three out of four signs were treated as scabies. They were also asked questions concerning pruritus in the family/among friends, past treatment, school break at home, and personal hygiene related to taking bath and cleaning the clothes and fomites. The interview used prepared questionnaires in Indonesian language. 


\section{Results}

The subjects consisted of 50 girls and 55 boys, aged ranging from 11-15 years old, from the year 7 through 9 classes. Overall, scabies was diagnosed in $76.9 \%$ subjects.

Factors related to scabies transmission were presented in Table 1. The questions are translated into English in this report.

From the fact that scabies is easily transmitted among family members, and that patients from boarding schools when seeing the doctor are accompanied by parents who commonly suffer from the same disease, it is important to investigate the degree of exposure to the household members. As high as $79 \%$ subjects took school breaks more than twice a year at home. This, combined with poor attitude toward personal hygiene described below, would potentially make scabies a perpetual infestation. Bathing regularly with soap did not seem to be an issue, as well as use of towel. However, $75.2 \%$ subjects sometimes shared clothes with their friends/siblings, and to lesser degree $(50.4 \%)$ their prayer attire. Some subjects admitted they had no sparing clean clothes. Among the attires they often share was baju koko, a shirt usually white in color with long sleeves used in (regular, five-time daily) prayer. The habits of sharing clothes did not differ between genders. However, they did, regarding the frequency of washing. As high as $68.5 \%$ subjects admitted they had used the clothes for some days before washing, and the large proportion in this group was male students $(78 \%$ of their numbers). A large proportion of subjects claimed they ironed the shirts, but many of them did not think warm water available for washing clothes. Only less than $20 \%$ subjects did not wash bed linens. The data must be considered carefully, because some of the subjects did not use pillow cover or blanket at all. That was one of the reasons why most subjects did not share bedding items with their friends/siblings. Some even claimed to sleep just on the floor, or on large mattress without sheet, with the other most junior students. Sleeping on a sibling/friend's bed was found in majority of subjects (75\%).

The presence of persons carrying the mite among them was high $(88.5 \%)$, and even though as high as $71 \%$ had received treatment, the symptoms appeared again according to the large portion (73\%) of the subjects.

\section{Discussion}

Most of findings in this study mirrored those conducted in similar boarding schools in other parts of Indonesia. On sharing personal items, there were some interesting findings. Widuri, et al. ${ }^{2}$ found that sharing towels among students increased the risk of getting scabies by 3.4 times. While it was supported by literature, ${ }^{1-5}$ most subjects in our study did not do it. On the contrary, sharing clothes and prayer attire was common among them that we thought it might interfere with the treatment in the future. The habits might relate to socioeconomic background, as some participants admitted

Table 1. Factors related to scabies transmission among boarding school students $(\mathrm{N}=105)$.

\begin{tabular}{|c|c|}
\hline Questions & Responses (n) \\
\hline In a year, how many times do you take a school break at home? & $\begin{array}{l}\text { More than twice a year (83) } \\
\text { Twice or less (7) }\end{array}$ \\
\hline How many times in a day do you took bath with soap? & $\begin{array}{l}\text { More than twice (24) } \\
\text { Twice (71) } \\
\text { Less than twice (8) }\end{array}$ \\
\hline Do you share towel with your friends/siblings? & $\begin{array}{l}\text { No }(92) \\
\text { Yes }(9)\end{array}$ \\
\hline Do you share clothes with your friends/siblings? & $\begin{array}{l}\text { Sometimes (79) } \\
\text { Never (24) }\end{array}$ \\
\hline Do you share prayer attire (sarong, mukena, baju koko) with your friends/siblings? & $\begin{array}{l}\text { Sometimes ( } 53) \\
\text { Never }(49)\end{array}$ \\
\hline Do you wash the clothes right after its use? & $\begin{array}{l}\text { Yes (29) } \\
\text { No, sometimes after 2-3 days of use (72) }\end{array}$ \\
\hline Do you wash bed linens (pillow cover, sheet, blanket)? & $\begin{array}{l}\text { Yes }(69) \\
\text { No }(19)\end{array}$ \\
\hline Do you regularly put bed mattress under the sun? & $\begin{array}{l}\text { Yes }(71) \\
\text { No }(26)\end{array}$ \\
\hline Is warm water available for washing your clothes? & $\begin{array}{l}\text { Yes }(44) \\
\text { No }(54)\end{array}$ \\
\hline Do you iron your clothes? & $\begin{array}{l}\text { Yes (77) } \\
\text { No (24) }\end{array}$ \\
\hline Do you sometimes sleep on your friend/sibling's bed? & $\begin{array}{l}\text { Yes (79) } \\
\text { No (17) }\end{array}$ \\
\hline Do you sometimes borrow your friend/sibling's pillow, blanket? & $\begin{array}{l}\text { Yes (30) } \\
\text { No }(61)\end{array}$ \\
\hline Do you have friend/sibling suffering from the same itchy condition as you are? & $\begin{array}{l}\text { Yes }(93) \\
\text { No }(3)\end{array}$ \\
\hline Do they ever receive treatment? & $\begin{array}{l}\text { Yes (75) } \\
\text { No (12) }\end{array}$ \\
\hline Does their itch appear again? & $\begin{array}{l}\text { Yes (77) } \\
\text { No (10) }\end{array}$ \\
\hline
\end{tabular}


they have no sparing items. Also, some participants, especially the younger ones, still had their clothes washed at home by their mothers who picked/delivered them only 23 times a week.

Strangely, however, Widuri, et al. ${ }^{2}$ found that sharing clothes/prayer attire lower the risk by 0.3 times. Sharing clothes might pose a different risk compared with prayer attire. The latter might be worn for only a short time, perhaps less than $30 \mathrm{~min}$ utes, so that the risk of transmitting scabies was thought to be lower. However, the risk might be higher among our participants because they did not wash the clothes regularly and thus risking prolonged contact with infectious materials.

The baju koko shirt that was frequently shared in this study is actually not mandatory in prayer - unlike mukena for women but its use is very frequent in religious event/school. Unsuspecting physician unfamiliar with the habits donning prayer attire might miss this information when educating scabies patients.

It should be noted that other investigators, Yasin et al. $^{3}$ found that personal hygiene (frequency of bathing, sharing towels and clothes) was not a significant factor. Instead, they found room sanitation (defined as clean water availability) correlated with scabies. Clean water was available in the boarding school of our study, but the subjects did not think hot water was available for washing the clothes. To ensure killing of the mites, literature suggests using at least 50 -degree Celsius water. ${ }^{1}$

Bedding was the greater problem among our findings; it was used by so many students together, and some of them did not use sheet to cover the mattress. Direct contact with skin would cause mites to drop on the surface and as the mattress was not washed, the parasites would stay longer and be able to infect other people quite readily. Widuri, et al. ${ }^{2}$ found that sleeping together in close spaces among the students increased the risk by 21 times. We think this would be the greatest obstacle in treating scabies: while the students might be educated on personal hygiene, providing spare, new mattresses requires coordination with the school board of directors, and large funding. If they could not be washed, old mattresses should be left unused for at least 3 days, or longer, or might have to be discarded.

There were other studies regarding factors related to scabies in boarding school in Indonesia. While stating that poor personal hygiene was strongly correlated with scabies, study by Akmal, et al. ${ }^{4}$ in Sumatra only vaguely mentioned sharing personal items as one of the factors. Study by Nuraini, et al. ${ }^{5}$ found that level of knowledge was significantly correlated with scabies prevalence. However, what constituted the knowledge was not clearly defined.

Failure to address these factors seemed to have led to persistence of scabies, as illustrated by the high percentage of subjects reporting past treatment of their friends/siblings, only to have their symptoms returned after some time. We predict future mass treatment to these students must also cover their family members at home. Large numbers of participants reported the same symptoms in their siblings (or even parents). The transmission might occur during school holidays, when most of them returned home. Those family members, if untreated, would in turn be the source of infection. When conducting such treatment in the future, we plan to document factors that might hinder the proper application of drugs, by the students and also their family members, and other related issues.

\section{Conclusions}

The findings in our study was not markedly different with those of previous ones, in that personal hygiene and environment mattered the most in scabies cases.
Our study tried to specify the problems so that future mass treatment might address them correctly; if not, a very large sum of money spent on the drugs would have been wasted. Providing clean clothes and bedding, and developing environment that promote good hygiene, seemed to be the key issues. We realize that our study may not be a good representation of boarding school condition in Indonesia. Our findings should not be generalized; rather, we advise to use them as a reference to address scabies problems in boarding schools setting.

\section{References}

1. Burkhart CN, Burkhart CG. Scabies, other mites, and pediculosis. In: Goldsmith LA, Katz SI, Gilchrest BA, Paller AS, Leffell DJ, Wolff K, eds. Fitzpatrick's Dermatology in General Medicine. 8th ed. New York: McGrawHill Medical, 2012. pp. 2569-2572.

2. Widuri NA, Candrawati E, Masluhiya S. Analysis of risk factor for scabies among students of Nurul Hikmah boarding school, Kebonagung Village, Kecamatan Pakisaji, Malang Regency. Nursing News 2017;2:622-33.

3. Yasin. Scabies prevalence and dan related factors among students of Darul Mujahadah boarding school, Tegal Regency, Central Java Province, October 2009. [unpublished thesis].

4. Akmal SC, Semiarty R, Gayatri. Correlation between personal hygiene and scabies in Darul Ulum boarding school, Palarik Air Pacah, Kecamatan Koto Tangah Padang, 2013. 2018; Available from: http://jurnal.fk. unand.ac.id.

5. Nuraini N, Wijayanti RA. Risk factor for scabies at Nurul Islam boarding school, Jember. J Ilmiah Inovasi 2016;1:137-41. 